\title{
ADROIT AQUACULTURE SURVEILLANCE SYSTEM
}

\author{
Avinash Wilson $\mathbf{J}$ \\ Department of IT \\ LICET, Chennai, India
}

\author{
Anusha P \\ Department of IT \\ LICET, Chennai, India
}

\author{
Arun P \\ Department of IT \\ LICET, Chennai, India
}

\begin{abstract}
Aquaculture is one of the indispensable fields that helps in the chain of nourishment by feeding the world's growing population, with 93.6 million metric tons to meet the world's seafood needs by 2030 . Internet of Things (IoT) or Internet of Everything is a blooming paradigm that changes the way of interaction with the environment, which has global attention of the industries in its rapid growth. Incorporating the IoT in the observation of seafood cultivating procedures can improve the productivity and supportability while upgrading the business with the next generation technologies. In Aquaculture, a handful of units are set-up in the deep seas, while the majority of the units are set inland. In inland offices, the ocean organisms are cultured in tanks that can change in volumes and materials. In such cases where profitable aquaculture is done, numerous endeavors are taken to augment the well-being of the sea creatures. Here, we are proposing an exceptionally beneficial aquaculture framework, designed for the aquafarming unit employments, for observing the quality of the water, controlling the system's irregularity and providing real-time updates to the aqua-farmer. The Aqua-Farmer can surveille the units and control the water circulation remotely through a mobile application.
\end{abstract}

Keywords - Aquaculture, Aqua-Farmer, Inland, Internet of Everything, Well-Being

\section{INTRODUCTION}

Aquaculture is the controlled process of cultivating aquatic organisms, especially for human consumption. This activity has a great importance in economic development and food production. The Global Aquaculture Alliance (GAA) estimates that, by the year of 2030, 62 percent of all seafood produced for human consumption will come from aquaculture. Also, aquaculture production is projected to grow from 47.2 million metric tons in 2006 to 93.6 million metric tons by 2030, while wild fisheries production is expected to decline from 64.5 million metric tons to 58.2 million metric tons during that same time. To feed the world's growing population, aquaculture has to come up with an additional 46.4 million metric tons to meet the world's seafood needs.

Continuous monitoring of the physical, chemical and biological parameters of aqua-farms helps not only to predict and control the negative conditions of aquaculture, but also to avoid environmental damage and the collapse of the production process. Moreover, the people that work in the aqua-farms have to be engaged in all day activities to maintain the living species habitat which is not possible at times. In this direction, our project aims to present a smart surveillance system that is used for the monitoring and maintenance of an aqua-farm. This includes: $\mathrm{pH}$ level, turbidity, temperature, chemical element level (NH3) followed by a motor mechanism that helps in sending the filthy water out and fresh water in. These are vital to maintain adequate conditions and avoid undesirable situations that may lead to the collapse of aquaculture systems. All of these parameters and the status of the farm will be updated in the mobile app using a real-time cloud service.

\section{SYSTEM ARCHITECTURE}

The proposed system (as shown in figure 1) is to monitor an aquaculture unit's various indispensable quality parameters and to notify the status of the unit to the aqua-farmer through a realtime mobile application.

When the Equipment is turned on, the following quality parameters are monitored:

- Temperature

- $\mathrm{pH}$

- Ammonia

- Turbidity

The sensor values are periodically collected and updated in the real-time Cloud Service i.e.) BLYNK. The AquaFarmer's mobile application retrieves the values from the Cloud and creates the alert as notifications and pop-up 


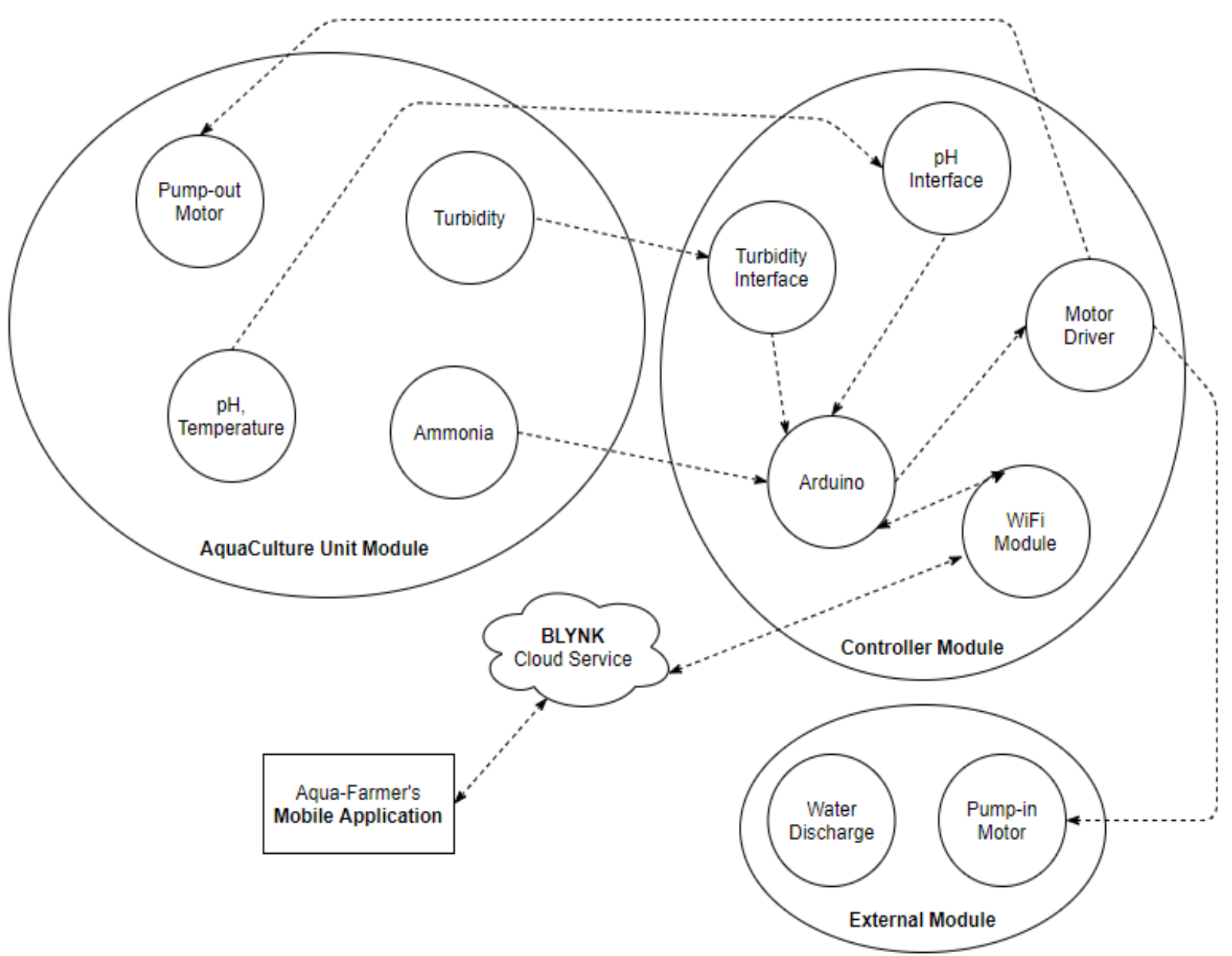

Fig. 1. System Architecture of the Adroit Aquaculture Surveillance System

dialog boxes. Whenever the quality parameter's range is violated, the aqua-farmer is notified with an urgent message. This system also includes a feature which allows the aquafarmer to have a control over the water circulation mechanism of the aquaculture unit i.e.) whenever the quality parameters range is violated (for instance, the value of temperature exceeding than the specified value) the aqua-farmer can remotely turn ON the water supply through his/her mobile application, so that the filthy water is pumped-out while the freshwater is pumped-in.

\section{Methodology}

\section{A. Arduino Uno}

Arduino Uno is used as the controller board on which the components are connected.

\section{B. ESP 8266}

ESP-8266 is the Wi-Fi Module that is used to send the sensor readings to the Blynk Cloud Service and retrieve the "run" command from the aqua-farmer's mobile application.

\section{C. pH sensor}

Analog $\mathrm{pH}$ Sensor kit is used to measure the $\mathrm{pH}$ value of the water and the temperature of the unit using the integrated compensation circuit. The $\mathrm{pH}$ interface is used to connect the $\mathrm{pH}$ probe and the Arduino.

\section{RKI 5163}

The turbidity sensor works on the infrared transmission and reception principle to monitor the turbidity intensity of the unit.

\section{E. DC 3-6V (pump)}

The Micro Submersible Pump is used to demonstrate the pumpout mechanism of the filthy water and the pump-in mechanism of the freshwater. 

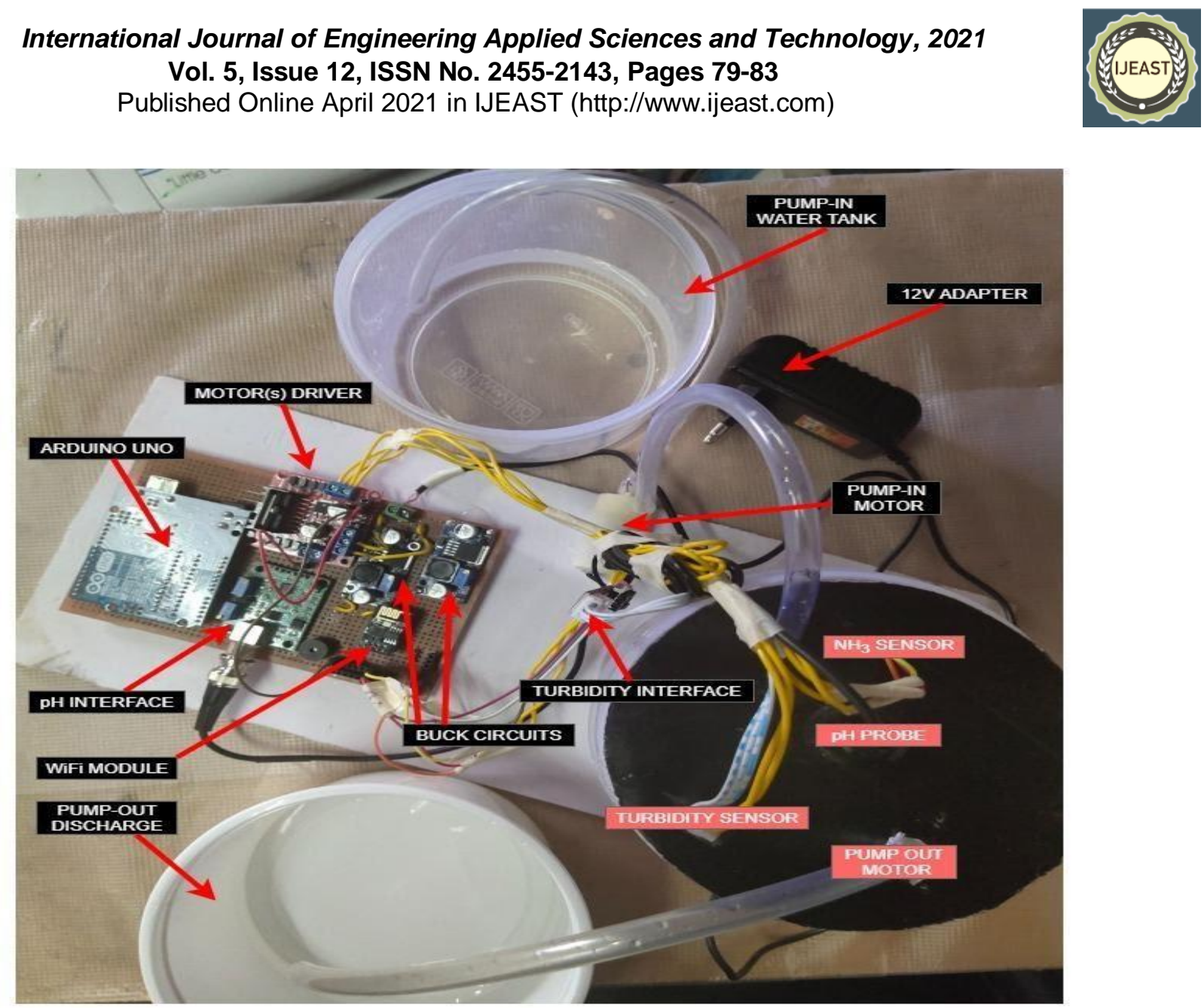

Fig. 2. Aqua-Farm Unit Hardware

\section{F. L298N Motor Driver}

The Motor Driver is a relay mechanism used to interface the arduino with the Mini Motor pumps to operate them simultaneously.

\section{G. MQ135}

The MQ-135 Air Quality gas sensor is used to check the Ammonia content released by the water in the aquaculture unit.

\section{H. LM2596S Buck Convertor}

Since a $12 \mathrm{~V}$ power adapter is used in the module, in order to supply $3.3 \mathrm{~V}$ to the ESP-8266 and 5V to the Arduino Uno, the Buck Convertors are used as a step-down mechanism.

\section{EXPERIMENT AND RESULT}

\section{A. Aqua-Farm Unit Hardware -}

The aqua-farm unit's hardware (as shown in figure 2) consists of a $\mathrm{pH}$ meter to measure the $\mathrm{pH}$ value and temperature in the water, a turbidity sensor to check the water quality, MQ135-gas sensor to measure the level of ammonia content released from the water, Micro DC 3-6V(pump) to circulate the water and Wi-Fi Module (ESP 8266) to send the values to the BLYNK cloud service.

\section{B. Aqua-Farmer Mobile Application -}

The Aqua-Farmer application (as shown in figure 3) is built on BLYNK cloud service. The app retrieves values such as the temperature, $\mathrm{pH}$ level, ammonia content, turbidity of the aquaculture unit from the cloud and displays it, also a notification alert is given to avoid emergency situations. The app also provides a feature where-in, the aqua-farmer can turn ON/OFF the motor which controls the water supply to the pond. When the application is offline, the last updated value in the blynk is displayed in the application.

\section{CONCLUSION}

This IoT based Adroit Aquaculture Surveillance System serves as an efficient system for the inland aquaculture units. The system is relatively inexpensive and helps the aquafarmer notify the status of the aqua-farm unit in case of any needs. The equipment monitors the vital parameters of the aquaculture unit and if the parameter goes from normal range 


\section{International Journal of Engineering Applied Sciences and Technology, 2021 \\ Vol. 5, Issue 12, ISSN No. 2455-2143, Pages 79-83 \\ Published Online April 2021 in IJEAST (http://www.ijeast.com)}

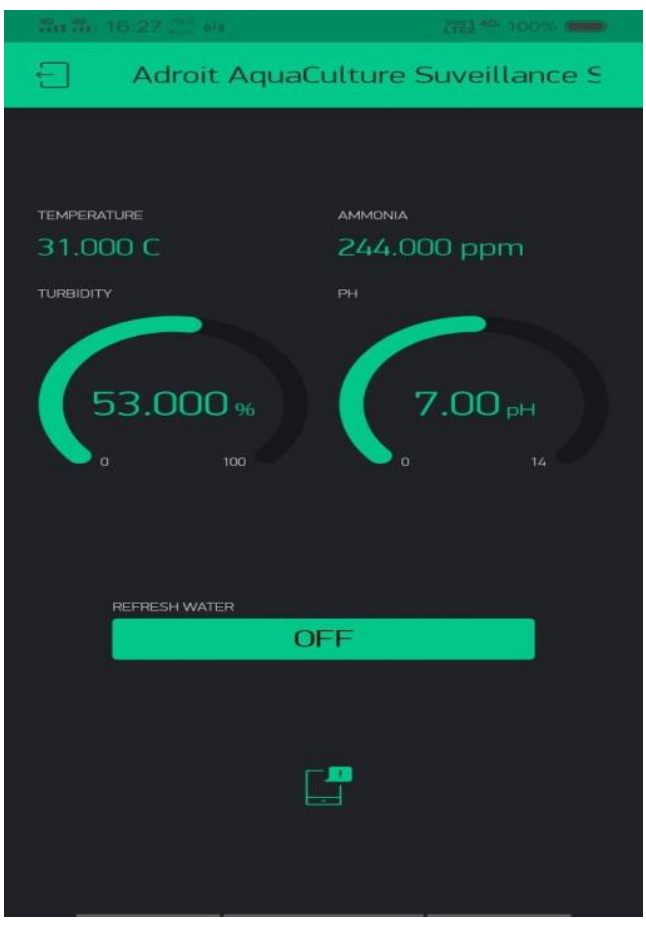

Fig. 3. Aqua-Farmer Mobile Application

to an unsafe range, the aqua-farmer is immediately notified so that critical care can be given to the unit before it reaches a dangerous state. Also, the aqua-farmer can remotely turn $\mathrm{ON}$ the water supply through his/her mobile application, so that filthy water is pumped-out while freshwater is pumped-in.

As every aquatic organism withstands different limits, such vital parameter limits can be set by the aqua-farmer (user) manually in the developed mobile application. In future, this system can be widely used in a variety of environmental monitoring settings, such as plant care systems etc. Combined with the Internet of Everything, regardless of where the unit is located, the user can use the instant messaging environment, taking real-time monitoring technology to the next level.

\section{ACKNOWLEDGEMENT}

We thank our project guide Ms B Prabha B.Tech., M.E., [AP/IT] for her knowledge, encouragement and guidance throughout the development of the project. Many thanks go to the contributors of the chapter for motivation and support. Their active and timely cooperation was a great thing for us.

\section{REFERENCE}

[1] Balakrishnan S,S Sheeba Rani, K C Ramya "Design and Development of IoT Based Smart Aquaculture System in a
Cloud Environment”. In International Journal of Oceans and Oceanography (11 January 2017)

[2] Cesar Encinas, Erica Ruiz, Joaquin Cortez, Adolfo Espinoza" Design and implementation of a distributed IoT system for the monitoring of water quality in aquaculture". Wireless Telecommunications Symposium (WTS) 2017

[3] De Silva SS, Soto D, 2009, "Climate change and aquaculture: Potential impacts, adaptation and mitigation. In Climate change implications for fisheries and aquaculture: overview of current scientific knowledge", eds. K. Cochrane, C. De Young, D. Soto, and T. Bahri. FAO Fisheries and Aquaculture Technical Paper. No. 530, 151-212.

[4] Duy, N. T. K., Tu, N. D., Son, T. H., \& Khanh, L. H. D. (2015, March). Automated monitoring and control system for shrimp farms based on embedded system and wireless sensor network. In Electrical, Computer and Communication Technologies (ICECCT), 2015 IEEE International Conference on (pp. 1-5). IEEE.

[5] Espinosa-Faller, F.J.; Rendón-Rodríguez, G.E. 2012, “A ZigBee Wireless Sensor Network for Monitoring an Aquaculture Recirculating System". J.Appl. Res. Technol. 2012, 10, 380-387.

[6] Ismail, Naoki Shinohara, Sevia Mahdaliza Idrus Sutan Nameh, Wasana Boonsong, Suryani Alifah, Kamarul Hafiz Kamaludin, Toni Anwar "Development of Smart Aquaculture Quality Monitoring (AQM) System with Internet of Things (IoT) “ SASSP 20 March 2019)

[7] Kamarul Hafiz Kamaludin, W. Ismail "Water quality monitoring with internet of things (IoT) “. In IEEE Conference on Systems, Process and Control (ICSPC) Dec 2017

[8] P. Y. Yang, J. T. Tsai, J. H. Chou, W. H. Ho and Y. Y. Lai, "Prediction of water quality evaluation for fish ponds of aquaculture," 2017 56th Annual Conference of the Society of Instrument and Control Engineers of Japan (SICE), Kanazawa, 2017, pp. 545-546.

[9] S. K. Vaddadi, Development of Embedded Wireless Network and Water Quality Measurement Systems for Aquaculture, Sixth Int. Conf. Sens.Technol. Dev., pp. 637641, 2012.

[10] Lee, P. G. (1995). A review of automated control systems for aquaculture and design criteria for their implementation. Aquacultural Engineering, 14(3), 205-227.

[11] Hu, S. (2015, July). Dynamic monitoring based on wireless sensor networks of IoT. In Logistics, Informatics and Service Sciences (LISS), 2015 International Conference on (pp. 1-4). IEEE.

[12] Duy, N. T. K., Tu, N. D., Son, T. H., \& Khanh, L. H. D. (2015, March). Automated monitoring and control system for shrimp farms based on embedded system and wireless sensor network. In Electrical, Computer and Communication Technologies (ICECCT), 2015 IEEE International Conference on (pp. 1-5). IEEE.

[13] Zhao, J. (2014). Research on Wireless Sensor Network in Aquaculture. In Applied Mechanics and Materials (Vol. 686, pp. 397-401). Trans Tech Publications. 
International Journal of Engineering Applied Sciences and Technology, 2021

Vol. 5, Issue 12, ISSN No. 2455-2143, Pages 79-83

Published Online April 2021 in IJEAST (http://www.ijeast.com)

[14] Espinosa-Curiel, I., \& Rodr, J. (2016, February). A mobile platform for remote monitoring of water quality on live fish transport containers:

[15] Lessons learned. In 2016 International Conference on
Electronics,
Communications
and
Computers

(CONIELECOMP) (pp. 40-47). IEEE.

[16] Sung, W. T., Chen, J. H., \& Wang, H. C. (2014, April).

Remote fish aqua-culture monitoring system based on wireless transmission technology. 